\title{
USER STORIES METHOD AND ASSISTIVE TECHNOLOGY PRODUCT DEVELOPMENT: A NEW APPROACH TO REQUIREMENTS ELICITATION
}

\author{
Zacharias, Isabela Cristina Simões; Campese, Carina; Santos, Thiago Bertolini dos; Cunha, \\ Lorena Pereira da; Costa, Janaina Mascarenhas Hornos \\ University of São Paulo
}

\begin{abstract}
Requirements elicitation for assistive technology (AT) product development must be collaborative and systemic. This process must ensure that the needs of all different users are identified. For this, UCD methods introduce different tools that seek user involvement and their needs identification. One method commonly used in software development is User Stories. The aim of this paper is to analyse the use of User Stories for requirements elicitation in an AT product development project. This method was applied with three types of users: patients, companions and occupational therapists. For the involvement of these users, the method was customized and two main adaptations were adopted: the stories were written by the development team and all user needs were identified through observations of interactions between patients and prototype. As a result, the development team was able to identify numerous product requirements to be used in later development phases. These requirements were generated by the user needs identified with User Stories. Thus, the method with necessary adaptations, was efficient for requirements elicitation in the AT product development process.
\end{abstract}

Keywords: Requirements, User centred design, Collaborative design

\section{Contact:}

Zacharias, Isabela Cristina Simões

University of São Paulo

Production Engineering

Brazil

isabela.zacharias@gmail.com

Cite this article: Zacharias, I.C.S., Campese, C., Santos, T.B., Cunha, L.P., Costa, J.M.H. (2019) 'User Stories Method and Assistive Technology Product Development: A New Approach to Requirements Elicitation', in Proceedings of the 22nd International Conference on Engineering Design (ICED19), Delft, The Netherlands, 5-8 August 2019. DOI:10.1017/dsi.2019.385 


\section{INTRODUCTION}

The product development process comprises a phase of user requirements identification (Ulrich and Eppinger, 2012). This is when the development team seeks to understand the user needs for the specific product, making it an important step in the development process (Rozenfeld et al., 2006). This importance is not different when developing Assistive Technology (AT) products. AT is "[...] an interdisciplinary area of knowledge, which includes products, resources, methodologies, strategies, practices, and services, that aim to promote the functionality related to the activity and participation of people with disabilities, incapacities or reduced mobility seeking autonomy, independence, quality of life and social inclusion [...]" (Brasil, 2009, p. 9). There is a big tendency in Brazil towards the development of AT products (Campese et al., 2016). While discussing product development, the requirements elicitation must be made with a systemic approach, with the goal of gathering different needs from different users (Martin et al., 2006; ABNT NBR IEC 60601-1-6, 2011).

All traditional methods of requirements elicitation are focused in obtaining user data according with project needs (Rozenfeld et al., 2006). However, these methods do not provide enough tools for the initial user identification and collaboration. A good model for product development can be seen in the principles of User-Centered Design (UCD), the users are involved starting at the initial phases, as a way to gain understanding about their requirements (Vredenburg et al., 2002; Abras, Krichmar and Preece, 2004). One well known UCD method for user needs identification is User Stories (US) (Campese et al., 2015).

US involves users to collect their needs inside the context of use (Alexander and Maiden, 2004). This method is an agile tool that tries to simplify the elicitation of needs, giving a clear understanding about the requirements and improving communication between developers and users (Leffingwell and Behrens, 2010). Requirements are presented through the user perspective, and they describe a function or desire for the product by the user (Cohn, 2004). Many studies use this method in software development and its efficiency is already verified in this field (Oglio, 2006).

The challenges of developing physical products are different from the ones found in software's. Also, for the development of medical products, other factors need to be taken into consideration - the fulfillment of technical requirements and the involvement of a large number of users. This method may be beneficial for this type of product for presenting the needs in a simplified format, which allows a user focused development. However, the method is based on an effective communication, ensuring the transmission of information and an accurate application. Thinking about developments in which the user has difficulty to verbally express opinions, the communication must be detached from the speech, generating the need for a modification to stimulate its benefits.

Finally, this paper tries to answer the following research question: "User Stories can be used for requirements elicitation of AT products with the same efficiency as in software development?". The aim of this paper is to introduce the requirements elicitation phase, in a case study of an AT product (orthosis), with User Stories. The paper is written in the following order: Section 2 presents the literature review of main concepts; Section 3 describes the case study methods; Section 4 presents the research results - the process of gathering stories, the requirements identification, the evaluation of requirements obtained and the team satisfaction with the method; and lastly, Section 5 summarizes the results and discussions of this study.

\section{LITERATURE REVIEW}

Considering that there is not a specific regulation for the development process of AT products in Brazil, this paper uses the medical devices development process for comparisons, because of some similarities. The development of any medical device demands that all users interacting with it, are acknowledged during the product requirements definition. Since every user generally has different needs, the involvement of all enables the elicitation of specific requirements and helps reaching a better usability in the product (ABNT NBR IEC 60601-1-6, 2011).

Moreover, the medical devices regulatory agencies demand general conditions related to safety and reliability that must be fulfilled, so that the product can be suitable for commercialization (Schiro et al., 2017). Risk management related with usability is one of these conditions. It implicates not only the identification of all user profiles with each usual role, but also enforces the identification of the common use environment and of possible and predictable dangerous use situations. In other words, considering a common scenario of use, which are the potential use mistakes that are going to generate 
dangerous situations (ABNT NBR IEC 60601-1-6, 2011).Therefore, to obtain a product development focused in solving user problems, and in the fulfillment of the usability regulation, is essential to identify the needs of all different users and their product requirements.

Requirements can be defined as a condition or a necessary ability for a problem resolution or to reach a specific goal. This condition or ability is part of a system, that meets specifications and patterns (IEEE, 1990). Requirements can also be described as attributes that establish different criteria for acceptance of a product or service. The definition of a requirement is a key step for the project, because can directly impact its success (Paula Filho, 2000).

Requirements can be classified as functional and non-functional. Functional requirements are those that describe what the system must do, depending on the user actions. This means that they define the system functions. On the other hand, non-functional requirements usually identify and limit the system defining capabilities. Their purpose is to describe how something will be done (Chung et al., 2000; Paula Filho, 2000; Sommerville, 2011). Non-functional requirements can be abstract and vague, demanding special focus during the development process (Chung et al., 2000). Sommerville (2011) presents non-functional requirement as critical, and stresses that the lack of attention to them during the development process can generate serious consequences, such as the disablement of the entire system.

The requirements elicitation phase is crucial to find product requirements with better usability for the user. In this phase, the user needs are gathered and informed to developers (Zowghi and Coulin, 2005; Sharma and Pandey, 2014). Because of this, the elicitation process includes numerous activities that must ensure a good communication and collaboration between the development team and all users. Also, it is important that the elicitation happens with iterations during the project, considering results revaluations and validations with stakeholders (Zowghi and Coulin, 2005).

Traditional methods used for user needs identification usually do not ensure the information gathering with all product users. For example, during a QFD application, there is no step responsible for user identification or classification (Tran and Sherif, 1995). This characteristic can cause a huge impact in the result depending on the type of product. For medical devices and AT, one product can have many users with different needs (Das and Almonor, 2000; Shah, Robinson and AlShawi, 2009; Martin et al., 2010), so is very important to know who they are beforehand.

Different from traditional methods, if the development team uses UCD tools during the product development process, the tendency is that the focus is on the user. With the application of such methods, it is possible to collect inputs of user needs, and transform this information in decisions for the project (Gardan, 2017). There are many UCD methods that can be used together, for example: user identification, user needs identification, and concept validation with the user (Campese et al., 2015).

A popular Agile method, used to identify user needs in software development, is known as User Stories (US) (Oglio, 2006). The application of this method allows the direct involvement of all users, making it possible the identification of their needs (Bertholdo et al., 2014). The main benefits of this method are: allow the elicitation of needs in a simplified way, giving a clear understanding about the requirements and improving communication between developers and users (Leffingwell and Behrens, 2010).

The method specifies user needs through stories, and it is important that these stories describes functionalities of the product that brings value for the user (Oglio, 2006). Thus, requirements are presented through the user perspective, and point to a function or desire for the product by the user (Cohn, 2004).

These stories are gathered through conversations between users and developers. The stories are narrated by the user and written in small sentences, comprising user needs (Cohn, 2004). The method US involves users to collect their needs inside the context of use (Alexander and Maiden, 2004). Thus, these needs presents assertive descriptions, allowing a better understanding by the design team during the development process (Alexander and Maiden, 2004).

As the method identifies user needs through stories, an effective communication is crucial for a better method application (Leffingwell and Behrens, 2010). Since developers and users usually have different perspectives about the product, these stories allow a better communication between them. So, the developers can reach a better understanding of user requirements for that product (Leffingwell and Behrens, 2010). The advantage of collecting user needs through conversations is that the user feels more comfortable to express desires, needs and problems verbally - making it simple to write stories. (Cohn, 2004; Oglio, 2006; Leffingwell and Behrens, 2010) 
Traditionally, stories are written in cards by the user - in a specific pattern that identifies the user, the need, and explains the value added by the story. Each card contains only one story, facilitating its implementation (Rees, 2002). The use of cards also contributes to a better requirements management inside the development project, through a good visual management that allows the visualization of requirements by the entire team (Rees, 2002; Leffingwell and Behrens, 2010).

\section{METHODS}

The goal of this paper is to present the results obtained from applying User Stories for the gathering of requirements in an AT project. The method of research was a case study (Yin, 2011). The project was conducted during the development of an orthosis to assist children with cerebral palsy in daily activities, as eating and writing. The project was subjected to approval of the Ethics Committee number 65888317.0.0000.51.54 and had total duration of 24 months, in which 4 months were used for this specific study.

For the execution of this case study the following protocol of research was applied (Table 1):

Table 1. Protocol of research

\begin{tabular}{|l|l|}
\hline Location & Small University Teaching Hospital \\
\hline Duration & April/17 to July/17 \\
\hline Development team & $\begin{array}{l}\text { Usability team (responsible for the method application) } \\
\text { Product engineering team }\end{array}$ \\
\hline Users & $\begin{array}{l}3 \text { Patients } \\
3 \text { Companions } \\
3 \text { Occupational Therapists }\end{array}$ \\
\hline Research questions & $\begin{array}{l}\text { Which modifications are needed in the user stories method for its application } \\
\text { in AT projects? } \\
\text { Is it possible to stimulate the narration of user stories through conversations? } \\
\text { The prototype use supports the communication of users with the } \\
\text { development team? } \\
\text { The development team can associate user needs with product requirements? }\end{array}$ \\
\hline Data collection & $\begin{array}{l}\text { Use of scripts for conversations } \\
\text { Audio recording of conversations } \\
\text { Observations of prototype use } \\
\text { Filming and photography of user interaction with prototype } \\
\text { Logbook of usability team }\end{array}$ \\
\hline
\end{tabular}

The usability team, with five researchers (designers and engineers), was responsible for the application of the method and for the integration activities with the users. The engineering team, with five engineers (mechanical and material), was responsible for the execution of activities related with the development of the orthosis prototype, and further with the technical development completion and project submission for the patent registration. It is important to emphasize that the engineering team was also part of the activities related with the US and its posterior validation. Next, the case study results are presented.

\section{RESULtS}

\subsection{User stories method customization}

The execution of the US method followed the approach proposed by Cohn (2004). As mentioned, the project development for the medical field requires some adjustments in the usability methods, due to 
some specific conditions; as the large number of users, their different level of expertise, the difficulty of understanding, for instance. Thus, the goal of this project was to apply User Stories and evaluate the necessary changes for its utilization in medical fields, specifically for AT. The method was implemented following four main steps: (1) users identification and selection; (2) tools preparation; (3) interaction with users; and (4) stories registration and validation.

The goal of the first step was to identify and select key users for the method execution. Through a brainstorming session, the usability and engineering teams listed all potential users that could interact with the product. All potential users were considered, from users with a higher degree of contact with the product - patients - through users with smaller degree of contact - some health professionals.

The teams found a list of nine different users. Based on this list, they discussed which of them should be actively involved in the project. The crucial criteria for this decision was: value for the project and easiness of access for future involvement activities. The selected users were: the patient, the Occupational Therapist (professional responsible for the treatment with the orthosis) (OT) and the patient companion (person responsible for the patient daily care - usually a relative).

The usability team noticed that the US traditional method needed some adaptations to overcome difficulties of communication with the users. Usually the users are responsible for writing their own user stories, assuring a greater accuracy of their needs. However, in AT projects, the users hardly have skills to write their own stories, making this activity impracticable. The first modification in the method was related with the way stories are collected. The team decided to elaborate scripts for all conversations, seeking to encourage users to describe their stories. Therefore, the stories must be written by the usability team, from the conversations with all users.

The other method modification was related with the inclusion of an orthosis concept prototype, aiming to facilitate the communication of the development team with the users. Indeed, for innovative projects as this, users not always can envision the product to report their needs.

Thus, the goal of the second step of the method was to elaborate a script of conversations and to develop the prototype for the collection of stories. The usability team wrote scripts according with the expected contribution of each users selected. For example, the script for the Occupational Therapist was focused in understanding the user needs and the orthosis specificities, according with the treatment of each patient. The prototype was built by the product engineering team, based in researches about previously used orthosis.

The third step goal was to collect the User Stories. The conversation scripts were used with the users. The third need for change in the method was the creation of stimulus for the generation of the indirect patient stories told by other users. Since AT patients often have difficulty reporting stories, problems, and needs, the development team must collect such information within the possibilities. In this way, the patients' stories were collected through the parents' and OTs's stories. Thus, the development team sought to instigate the OTs and companions to report stories with the patient perspective. Also, user needs were observed based on the interaction of patients with the prototype. The orthosis prototype had a fundamental role allowing the usability team to collect information to be subsequently transformed in requirements. The conversations and interactions with the prototype were recorded.

The fourth step goal was to identify stories using the conversation logs from the previous step. For this, the usability team transcribed and registered the stories. The transcriptions were made for each user separately, this means that for each user the conversation logs were analyzed and the stories were written in cards. Each card had only one story. Finally, the usability and engineering team validated the stories. The cards were attached to a board and each story was read and discussed by both teams. The stories were then grouped according to a requirement similarity criteria. In the end, the teams generated a requirements list to be used in the next steps of the product development.

Figure 1 presents the steps - with the modifications - of the User Stories method. The AT development must allow the team to extract requirements straight from the patients. In many cases, the involvement of patients in AT development projects is difficult because of some users physical and cognitive limitations. The Users Stories customization through the use of a prototype allowed the identification of requirements for these users. 


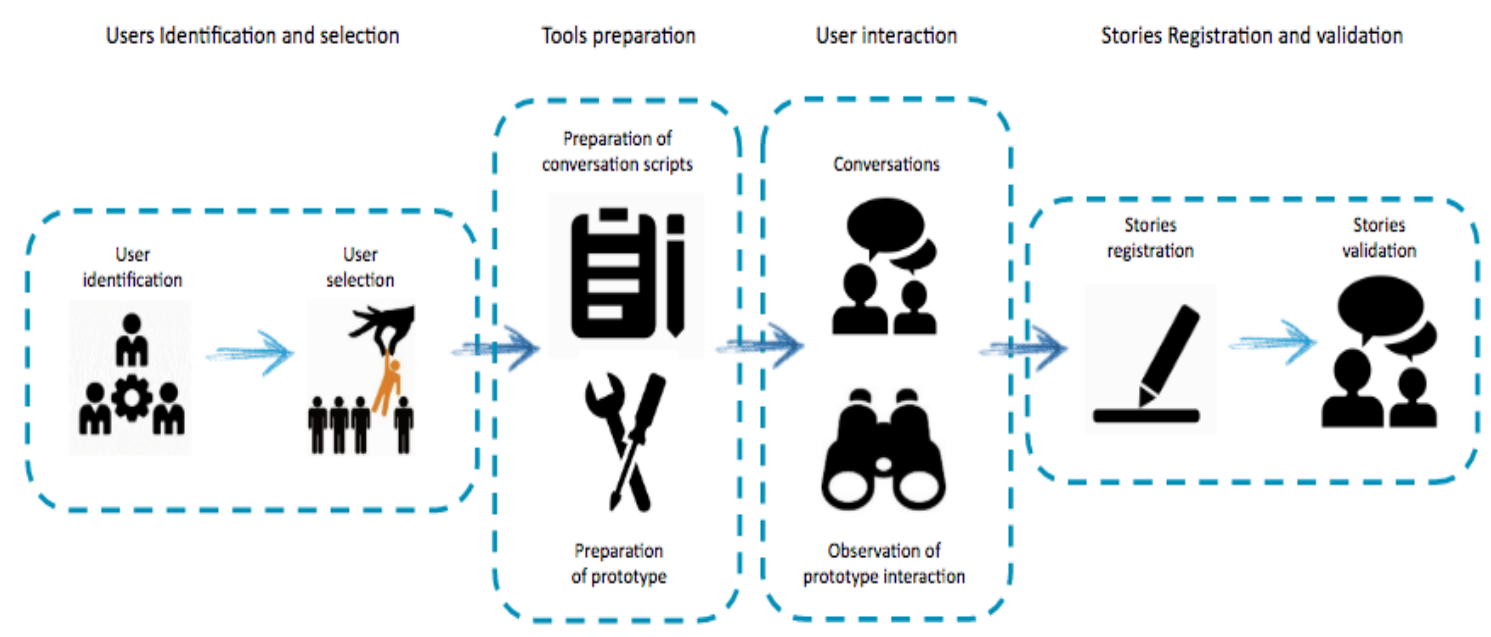

Figure 1. User Stories method customized for AT health projects.

Table 2 shows the comparison between the modified method for the orthesis development Project and the method found in the literature (traditional). It is possible to observe that the US method was mainly modified in the steps of interactions with users. For the traditional method, there are conversations with users that narrate their stories, which are written in cards by the user itself.

For the modified method, the usability team encouraged OT users and companions to narrate stories under the perspective of the patient. The team also observed the patients interacting with the orthosis prototype. Then, the stories were written by the team without the presence of the user. Since the user interaction was through the use of prototypes and through talks with companions and OT users, another step was added in the modified method: tools preparation.

This step was important for the prototype development by the engineering team and the preparation of the interviews' was important to guide the conversation with OT users and companions.

Table 2. Comparison between Modified User Stories method and Traditional method

\begin{tabular}{|l|l|l|}
\hline Step & Modified method & Traditional method \\
\hline \multirow{3}{*}{$\begin{array}{l}\text { 1 - User } \\
\text { identification and } \\
\text { selection }\end{array}$} & Brainstorming for user identification & $\begin{array}{l}\text { Users defined by the software } \\
\text { project }\end{array}$ \\
\cline { 2 - 3 } 2- Tools preparation & $\begin{array}{l}\text { User selection based in different } \\
\text { criteria (value for Project and ease of } \\
\text { access) }\end{array}$ & Involvement of all users \\
\cline { 2 - 3 } & Interviews scripts preparation & There is no script preparation \\
\hline \multirow{3}{*}{ 3- User Interaction } & $\begin{array}{l}\text { Encouraging OT users and companions } \\
\text { users to tell stories about the patient } \\
\text { user's perspective }\end{array}$ & $\begin{array}{l}\text { Conversations with users that tell } \\
\text { their stories }\end{array}$ \\
\cline { 2 - 3 } & $\begin{array}{l}\text { Observation of interaction between } \\
\text { patient user and prototype }\end{array}$ & There is no observations \\
\hline \multirow{2}{*}{$\begin{array}{l}\text { 4- Stories } \\
\text { registration and } \\
\text { validation }\end{array}$} & $\begin{array}{l}\text { Stories written after the interaction } \\
\text { with users }\end{array}$ & $\begin{array}{l}\text { Stories written during conversations } \\
\text { between developers and users }\end{array}$ \\
\cline { 2 - 3 } & $\begin{array}{l}\text { Stories written in cards by the usability } \\
\text { team }\end{array}$ & Stories written in cards by users \\
\hline
\end{tabular}

\subsection{User requirements identification with user stories}

In total 20 stories were gathered: 4 for the patient, 5 for a companion (mother of the patient) and the other for the OT. The stories can be seen in Table 3. The stories were transcribed according to the 
format given by Cohn (2004): "as <user>, I would like < need $>$ because < value proposition>". It is worth point out that these stories were gathered through conversations with the selected users.

Table 3. User Stories

\begin{tabular}{|c|c|c|}
\hline ID & User Stories & User \\
\hline S01 & As mother, I would like the orthosis to provide a higher autonomy for the patient & \multirow{5}{*}{$\begin{array}{l}\text { Compan } \\
\text {-ions }\end{array}$} \\
\hline S02 & As mother, I would like the orthosis to have a proper angulation for the patient & \\
\hline S03 & As mother, I would like the orthosis do not limit the patient movement & \\
\hline S04 & As mother, I would like the orthosis to be adapted to the life context of the patient & \\
\hline S05 & $\begin{array}{l}\text { As mother, I would like the orthosis to be aesthetically pleasing because it is } \\
\text { important for the patient }\end{array}$ & \\
\hline S06 & As patient, I would like the device to be in a comfortable position & \multirow{4}{*}{ Patient } \\
\hline S07 & As patient, I would like the orthosis to be aesthetically pleasing & \\
\hline S08 & As patient, I would like the device to be closer to the claw movement & \\
\hline S09 & As patient, I would like the orthosis not to bother the arm region & \\
\hline S10 & As OT, I would like the wrist to be steady & \multirow{11}{*}{ OT } \\
\hline S11 & As OT, I would like the orthosis to provide learning opportunities & \\
\hline S12 & $\begin{array}{l}\text { As OT I would like the orthosis support to be dorsal, to release another stimulus } \\
\text { region }\end{array}$ & \\
\hline S13 & $\begin{array}{l}\text { As OT, I would like the material to have a clean look, because this is important for } \\
\text { companions }\end{array}$ & \\
\hline S14 & $\begin{array}{l}\text { As OT, I would like the orthosis to support the patient to develop some important } \\
\text { functions for the treatment }\end{array}$ & \\
\hline S15 & $\begin{array}{l}\text { As OT, I would not like ventral support because it would lose the stimulus of that } \\
\text { region }\end{array}$ & \\
\hline S16 & As OT, I would like the orthosis to contribute to daily activities & \\
\hline S17 & $\begin{array}{l}\text { As OT, I would like the handle to have adequate proportions so that the patient } \\
\text { won't get hurt }\end{array}$ & \\
\hline S18 & $\begin{array}{l}\text { As OT, I would like the patients to return for treatment because the follow-up is } \\
\text { needed }\end{array}$ & \\
\hline S19 & As OT, I would like the orthosis material to be resistant to avoid constant damage & \\
\hline S20 & As OT, I would like the orthosis to be adapted to the life context of the patient & \\
\hline
\end{tabular}

The five patient's companion stories, exhibits needs that would not be easily seen by an engineering team. This is because they go beyond functional aspects. For example, for S04 "As a mother I would like the orthosis to be adapted to the life context of the patient", the engineering team would need to understand the daily life of the patient to know their everyday activities. Because the patients were not able to talk (because of their deficiencies), their stories were generated through interviews with companions and OTs. These interviews provided that the patient needs were collected. On the other hand, the OTs needs were in great proportion, functional (e.g. steady wrist, and orthosis having a back support instead of frontal).

Because of the patients' limitations, the use of a prototype was crucial. This limitation context was reported as very frequent by the health team. The interaction of patients with prototype allowed the user involvement without the need of direct speech communication. Also, the users were encouraged to report stories under the patient perspective.

One example of how this interaction allowed the collection of patient requirements is story S08: "As a patient I would like the device to be closer to the claw movement". This story was identified through a conversation between companions and OTs about the way the orthosis can support daily activities like eating and writing. Thus, it was possible to identify that the orthosis should allow the development of a movement closer to the natural claw movement.

Some requirements were presented by more than one user, as in the case of S05 and S07, describing requirements related with the orthosis aesthetics. Stories S04 and S20 report the importance of the orthosis in daily activities for the patient. Stories S09 and S17 explicit the need of an orthosis that do 
not cause bruises. These converging requirements exhibit key points for the product development, since they return value for more than one type of user.

During the stories evaluation process, another characteristic was perceived in comparison with the traditional method: the stories were not associated with only one requirement. This means that one story could present more than one requirement or many stories could be grouped to establish only one requirement for the product. This fact was observed because the stories were related with physical products.

For the AT product development project, the stories explained in table 3 expresses the user requirements. These requirements are translated and understood as features that the product must comply with. These features are named product requirements (Rozenfeld et al., 2006). Thus, the user needs represented in stories are translated to product features to be added during development (Pressman, 2010).

The stories were grouped by similarity and discussed by the development team to translate needs in AT product features. Lastly, the stories were grouped in 11 product requirements: multifunctional (help the patient to execute different tasks related with eating and writing), comfort (appropriate dimensions, material and point of pressure), having options of angulation. modularity with different orthosis, dependency degree of OT, endurance (to falls), cleanliness (low roughness, rounding and color), water and soap resistance, customizable (color options), release stimulus region and do not limit finger movements.

\subsection{Analysis of quality for the user requirements collected with user stories}

The user stories method seeks to ensure that the product requirements are connected with the user needs. Considering that a good product development must involve users, this method obtains the requirements directly from them. The story S09 shows how the requirement is present under the user perspective about comfort: "As a patient, I would like the orthosis not to bother the arm region". In this project, is possible to assert that the added value of the method was perceived by both teams, because the requirements list was linked to the users' real needs.

The stories format makes easy to translate user needs in product requirements. Because it's an agile method, user stories allow user needs to be written in a simple form, making it clear for the development team. The story S10 "As a OT, I would like the wrist to be steady", shows that the stabilization of the wrist is very important, generating discussions about what product requirements could meet this need. Another example is story S12: "As a OT, I would like the orthosis support to be dorsal, to release another stimulus region", expresses in practical terms design features that were obtained. This type of description encouraged the development team to think about product requirements to meet this need.

User Stories shows in a clear way user desires and help identify its value. This helps the development team in interpreting and understanding this value for the user. For example, story S13 "As a OT, I would like the material to have a clean look, because this is important for companions" and S14 "As a OT, I would like the orthosis to support the patient to develop some important functions for the treatment", help the development team to come up with product requirements for a need that returns a specific value for the user.

\subsection{Method application satisfaction analysis}

The method has a learning curve in its application. In the beginning, it can be hard to realize the advantages that it brings. The engineering team only understood the value of information for the project in the validation phase, where every requirement was discussed. It is recommended the execution of a previous study, to understand the method in general, as well as an application of pilot tests before the real application.

The requirements consistency is an important criterial in product development. In the validation step, the teams validated each story and discussed if the requirements matched the project goals. This discussion was important for the understanding of requirements and for the clarification of doubts before future interactions. A good practice is to involve a great number of users, so that the requirements can be generalized, instead of customized. 
The method application brought a different perspective for the development team. After the requirements elicitation, they understood the problem from the user point of view. This allowed a different orientation of next phases, in which the product requirements were originated directly from the users.

The development team reported that the requirement gathering was effective through the stories. Even if the method cannot allow these users to directly write their stories, the team had very good results with the use of scripts. They also reported that the method allowed the understanding of users desires and needs. An example of this it Story S17: "As a OT, I would like the handle to have adequate proportions so that the patient won't get hurt".

For all involved: development team, usability team, and users, it was very clear the advantages of using a conversation script with the prototype. The users were able to report their stories interacting with the prototype, as shown in S02 "As a mother I would like the orthosis to have a proper angulation for the patient", in which the companion reported a need observed while the user interacted with the prototype. Finally, the development team was then very satisfied in understating why the needs for alterations were gathered.

\section{CONCLUSION}

This study presented one step of requirements elicitation of an orthosis development case, using User Stories. For this, some changes were needed, seeking the involvement of users in a collaborative way. The main change was related with the way stories are usually written; because of user limitations, the usability team wrote each one of them. Also, the user involvement was maximized by the use of a product concept prototype, as a way of improving communication between the development team and the users with cognition and speak problems.

The user stories were stimulated by conversations, with the goal of encourage users to report cases, experiences and facts that would be translated in needs. The users had a better and clear communication while interacting with the prototype, and the observations of these interactions allowed the identification of stories, that would be otherwise very difficult.

The environment of conversation between users and developers allowed the users to feel more comfortable. The communication was informal and enabled the users to feel less pressure. The stories originated from narratives showed a better consistency with the user's reality.

User needs were easily transformed in product requirements by the product engineering team. The user stories format supports the translation of needs in requirements. The possibility of discussing product requirements from user inputs is very valuable for the project, since it not only helps the development of a user-focused solution, but also allows the team to have a better understanding of the requirements. Also, in medical devices and AT development projects, during the requirements elicitation phase usually, it is commun that developers do not have any activity for the identification of all users, and do not actively involve users; being this the cause of many difficulties in the creation and prioritization of strong requirements, preventing the seek for a better product usability.

The User Stories method can be used in requirements elicitation in AT product development. However, given the context and the potential users (patients with physical and/or cognitive impairment are often not able to express their needs or even express themselves in any way), the method demands adaptations to fit the reality. Patient information should be identified in the best possible way, so the development team should interact with people in their everyday lives. In this case, the adaptation of the method by the use of a prototype, allowed the involvement of an important user of AT devices, the patient. Thus, the method can be used in AT product development with a similar efficacy gained in software development; provided that the necessary reformulations for a collaborative development are made. In addition, this model can be used and tested for further product developments, including other areas of expertise.

\section{REFERENCES}

ABNT NBR IEC 60601-1-6 (2011), Equipamento eletromédico Parte 1-6: Requisitos gerais para segurança básica e desempenho essencial Norma colateral: Usabilidade.

Abras, C., Krichmar, D.M. and Preece, J. (2004), “User-Centered Design”, Encyclopedia of Human-Computer Interaction.

Alexander, I.A.N. and Maiden, N. (2004), Scenarios, stories, use cases, John Wiley \&Sons Ltd, England. 
Bertholdo, A.P.O., Da Silva, T.S., De O. Melo, C., Kon, F., and Silveira, M.S. (2014), “Agile usability patterns for UCD early stages”, In: A. Marcus, (Ed.), Design, User Experience, and Usability. Proceeding. Crete, Springer, Greece, pp. 33-44. http://dx.doi.org/10.1007/978-3-319-07668-3_4.

Brasil, S.N., de P. dos D. da P. com D. (2009), Tecnologia Assistiva, CORDE, Comitê de. Brasília.

Campese, C., Scatolin, J.L., Esposto, R.F.S. and Costa, J.M.H.d. (2015), "Estudo dos métodos de UCD”, $10^{\circ}$ Congresso Brasileiro de Gestão da Inovação e Desenvolvimentos de Produtos, Itajubá - MG, pp. 1-12.

Campese, C., Silva, T.N.R.d., Silva, L.L.G.d., Figueiredo, J.P. and Menegon, N.L. (2016), “Assistive technology and passengers with special assistance needs in air transport: contributions to cabin design", Production, Vol. 26 No. 2, pp. 303-312.

Chung, L., Nixon, B.A., Yu, E. and Mylopoulos, J. (2000), Non-functional requirements in software engineering. 1st editio, Springer Science+Business Media, New York. http://dx.doi.org/10.1007/978-14615-5269-7.

Cohn, M. (2004), User Stories Applied: For Agile Software Development, Addison Wesley.

Das, S.K. and Almonor, J.B. (2000), "A concurrent engineering approach for the development of medical devices”, International Journal of Computer Integrated Manufacturing, Vol. 13 No. 2, pp. 139-147. doi: $10.1080 / 095119200129984$

Gardan, J. (2017), “'Definition of users' requirements in the customized product design through a user-centered translation method", International Journal on Interactive Design and Manufacturing. Springer Paris, Vol. 11 No. 4, pp. 813-821. http://dx.doi.org/10.1007/s12008-015-0275-2.

IEEE (1990), IEEE Standard Glossary of Software Engineering Terminology, pp. 94.

Leffingwell, B.D. and Behrens, P. (2010), By Dean Leffingwell with Pete Behrens, pp. 1-16.

Martin, J.L., et al. (2010), Design for patient safety. User testing in the development of medical devices, National Patient Satefy Agency, London, p. 68.

Martin, J., Murphy, E.A., Crowe, J.A. and Norris, B. (2006), "Capturing User Requirements in Medical Device Development: The Role of Ergonomics”, Pshysiological Measurement, Vol. 27 No. 8, pp. R49-R62.

Oglio, P.D. (2006), Uma Ferramenta para Gerenciamento de Requisitos em Projetos Baseados em Extreme Programming, Universidade do Vale do Rio Dos Sinos.

Paula Filho, W. de P. (2000), "Engenharia de Software: fundamentos, métodos e padrões”, Manual do Engenheiro de Software, pp. 260.

Pressman, R.S. (2010), Software Engineering. A practitioner's approach. 7th edn, McGraw-Hill, New York.

Rozenfeld, H., Forcellini, F.A., Amaral, D.C., Toledo, J.C.d., Silva, S.L.d., Alliprandini, D.H. and Scalice, R.K. (2006), Gestão de Desenvolvimento de Produtos Uma referência para a melhoria do Processo, 1a Edição, Saraiva.

Shah, S.G.S., Robinson, I. and AlShawi, S. (2009), "Developing medical device technologies from users' perspectives: A theoretical framework for involving users in the development process", International Journal of Technology Assessment in Health Care, Vol. 25 No. 4, pp. 514-521.

Schiro, J., Pelayo, S., Weinhold, T., Del Zotto, M. and Marcilly, R. (2017), "Usability Validation of Medical Devices: Issues in Identifying Potential Use Errors", Building Capacity for Health Informatics in the Future, pp. 298-302. doi: 10.3233/978-1-61499-742-9-298.

Sharma, S. and Pandey, S.K. (2014), "Requirements Elicitation: Issues and Challenges", International Conference on Computing for Sustainable Global Development (INDIACom), pp. 151-155.

Sommerville, I. (2011), Engenharia de Software, 9.ed, Pearson Prentice Hall, São Paulo.

Tran, T. and Sherif, J.S. (1995), "Quality Function Deployment (QFD): An Effective Technique For Requirements Acquisition and Reuse", Conference Software Engineering Standards Symposium.

Ulrich, K.T. and Eppinger, S.D. (2012), Product Design and Development. Fifth Edit, McGraw-Hill Irwin, New York.

Vredenburg, K., Mao, J.-Y., Smith, P.W. and Carey, T. (2002), “A Survey of User-Centered Design Practice”, Design Methods, Vol. 4 No. 1, pp. 471-478.

Yin, R.K. (2011), Qualitative Research from Start to Finish, The Guilford Press, New York.

Zowghi, D. and Coulin, C. (2005), "Requirements Elicitation: A Survey of Techniques, Approaches, and Tools", in Engineering and Managing Software Requirements, pp. 19-46.

\section{ACKNOWLEDGMENTS}

This study was supported by Higher Education Personnel Improvement Coordination (Capes). The opinions, hypotheses, conclusions or recommendations expressed in this paper are of responsibility of the authors and do not necessarily reflect the views of Capes. The authors would like to extend sincere thanks to professor Zilda de Castro Silveira 